\title{
Surface water flooding, groundwater contamination, and enteric disease in developed countries: A scoping review of connections and consequences
}

\author{
L. Andrade \\ University College Dublin \\ J. O'Dwyer \\ University College Cork \\ E. O'Neill \\ University College Dublin
}

See next page for additional authors

Follow this and additional works at: https://arrow.tudublin.ie/ehsiart

Part of the Environmental Engineering Commons, and the Medicine and Health Sciences Commons

\section{Recommended Citation}

L. Andrade, J. O'Dwyer, E. O'Neill, P. Hynds, Surface water flooding, groundwater contamination, and enteric disease in developed countries: A scoping review of connections and consequences, Environmental Pollution, Volume 236, 2018, Pages 540-549, ISSN 0269-7491, DOI: 10.1016/ j.envpol.2018.01.104.

This Article is brought to you for free and open access by the ESHI Publications at ARROW@TU Dublin. It has been accepted for inclusion in Articles by an authorized administrator of ARROW@TU Dublin. For more information, please contact arrow.admin@tudublin.ie, aisling.coyne@tudublin.ie,gerard.connolly@tudublin.ie. Funder: Irish Research Council (IRC) \& Geological Survey of Ireland (GSI)

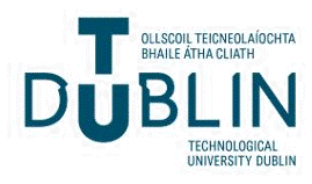




\section{Authors}

L. Andrade, J. O'Dwyer, E. O'Neill, and Paul Hynds

This article is available at ARROW@TU Dublin: https://arrow.tudublin.ie/ehsiart/32 


\title{
Surface water flooding, groundwater contamination, and enteric disease in developed countries: A scoping review of connections and consequences ${ }^{\text {th }}$
}

\author{
L. Andrade a, J. O'Dwyer ${ }^{\text {b }}$, E. O'Neill a, P. Hynds c, * \\ a School of Architecture, Planning \& Environmental Policy, University College Dublin, Ireland \\ b School of Biological, Earth and Environmental Sciences, University College Cork, Cork, Ireland \\ ${ }^{\mathrm{c}}$ Environmental Sustainability \& Health Institute, Dublin Institute of Technology, Ireland
}

\section{A R T I C L E I N F O}

\section{Article history:}

Received 28 November 2017

Received in revised form

23 January 2018

Accepted 30 January 2018

\section{Keywords:}

Enteric infection

Groundwater contamination

Flooding

Climate

Waterborne pathogens

\begin{abstract}
A B S T R A C T
Significant volumes of research over the past four decades has sought to elucidate the social, infrastructural, economic, and human health effects of climate change induced surface flooding. To date, epidemiological and public health studies of flooding events have focused on mental health effects, vector-borne diseases, and infectious enteric disease due to floodwater contact (i.e. typically low consumption rates). The inherent nature of groundwater (i.e. out of sight, out of mind) and the widely held belief that aquifers represent a pristine source of drinking water due to natural attenuation may represent the "perfect storm" causing direct consumption of relatively large volumes of surface floodcontaminated groundwater. Accordingly, the current study sought to systematically identify and synthesize all available peer-reviewed literature pertaining to the nexus between surface flooding, groundwater contamination and human gastroenteric outcomes. Just 14 relevant studies were found to have been published during the period 1980-2017, thus highlighting the fact that this potentially significant source of climate-related exposure to environmental infection has remained understudied to date. Studies differed significantly in terms of type and data reporting procedures, making it difficult to discern clear trends and patterns. Approximately 945 confirmed cases of flood-related enteric disease were examined across studies; these concurred with almost 10,000 suspected cases, equating to approximately 20 suspected cases per confirmed case. As such, no regional, national or global estimates are available for the human gastrointestinal health burden of flood-related groundwater contamination. In light of the demonstrable public health significance of the concurrent impacts of groundwater susceptibility and climate change exacerbation, strategies to increase awareness about potential sources of contamination and motivate precautionary behaviour (e.g. drinking water testing and treatment, supply interruptions) are necessary. Mainstreaming climate adaptation concerns into planning policies will also be necessary to reduce human exposure to waterborne sources of enteric infection.
\end{abstract}

() 2018 Elsevier Ltd. All rights reserved.

\section{Introduction}

Flooding represents one of the most devastating naturally occurring environmental hazards and has the potential to inflict major societal, infrastructural, and environmental damage (Barredo, 2007; Owrangi et al., 2014). Moreover, it is now widely

\footnotetext{
* This paper has been recommended for acceptance by Dr. Harmon Sarah Michele.

* Corresponding author.

E-mail address: hyndsp@tcd.ie (P. Hynds).
}

accepted that climate change will exacerbate the frequency and intensity of significant flood events into the future (Mousavi et al., 2011; Pall et al., 2011; Arnell and Gosling, 2016). For example, a recent high-resolution ( $1.5 \mathrm{~km}$ grid spacing) hydrological modelling study in the UK predicts increasing hourly rainfall during winter months, in addition to intensification of short-duration high-threshold rainfall events during summer periods, indicative of significant flash flooding (Kendon et al., 2014). Similarly, Arnell and Gosling (2016) used the $\mathrm{HadCM}_{3}$ and SRES $\mathrm{A}_{1} \mathrm{~b}$ climate models to predict that current 100-year floods will occur at least twice as frequently across $40 \%$ of the world, with approximately 450 million people and 430,000 $\mathrm{km}^{2}$ rural land affected by 2050 . 
While the structural damage and subsequent costs associated with flood events have and will likely continue to receive widespread media attention, (Devitt and O'Neill, 2017), far less attention is given to the potential adverse human health effects of these climatic events (Semenza et al., 2012).

Within the context of increasing flood frequency and severity, the subsequent mobilization of enteric pathogens within the environment, and particularly those from anthropogenic sources (e.g. inundated water treatment systems, septic tanks, and farmyards), followed by transmission of microbiologically rich material to rivers, coastal waters, and groundwater, represents an area of particular concern (Ivers and Ryan, 2006; Ten Veldhuis et al., 2010; De Man et al., 2014). The impact of extreme weather events has been shown to trigger waterborne disease outbreaks via infrastructural inundation, hydrological short circuiting/preferential flow, and subsequent consumption of contaminated water (Curriero et al., 2001; O'Dwyer et al., 2016). However, compared with flood-related infrastructural impacts, the increased exposure to waterborne pathogens is less well understood. Similarly, work on the socioeconomic costs of flooding events and climate change adaptation have tended to focus on river and coastal flooding (Rojas et al., 2013), with far less information available pertaining to public and private groundwater sources.

Groundwater represents the world's most extracted raw material ( $\approx 982 \mathrm{~km}^{3} /$ annum), and supplies approximately $31.5 \%$ (2.2 billion people) of the global population with domestic drinking water (Margat and Van der Gun, 2013; Murphy et al., 2017). For example, presently, 138.5 million Americans derive their daily drinking water from a groundwater source (US EPA, 2015). In high income countries, the widely held presumption that groundwater is a universally safe resource has resulted in undesirable practises (Charrois, 2010; Kreutzwiser et al., 2011; Hynds et al., 2013). Jin and Flury (2002) have shown that groundwater supplies are responsible for a disproportionate number of reported waterborne disease outbreaks. During the period 1971 to 2008, Wallender et al. (2014) identified at least 36 waterborne outbreaks reported to the Center for Disease Control and Prevention (CDC) Waterborne Disease and Outbreak Surveillance System (WBDOSS) which were associated with preceding heavy rainfall or flooding. Similar studies have shown that, even during relatively "normal" meteorological conditions, the contamination mechanisms associated with groundwater sources are intricate, temporal, localised, and frequently source-specific (Howard et al., 2003; Engström et al., 2017).

Notwithstanding the global importance of groundwater, the inherent complexities (and lack of understanding) associated with groundwater contamination mechanisms, and the increasing frequency and severity of flood events, to date, no comprehensive synthesis of the nexus between surface flooding, groundwater contamination, and the incidence of enteric disease has been published in the scientific literature. In isolation, these represent separate water security issues, however, in light of the potentially significant public health impacts of climate change, such a review is undoubtedly warranted. Accordingly, in order to acquire an improved understanding of the sources, pathways and receptors present at the interface between flooding, groundwater contamination and human gastrointestinal health, an exhaustive scoping review of relevant epidemiological and hydro (geo)logical studies has been undertaken. All pertinent data associated with exposures, mechanisms, and risk factors associated with flood-related, groundwater-borne enteric illness were extracted and homogenised. Due to a lack of consistent reporting and surveillance, in addition to auxiliary issues associated with waterborne infection in regions characterised by low levels of economic and social development (e.g. hygiene, (mal)nutrition, availability of healthcare services, etc.), the current review focused on high income regions, defined as developed economies, according to the World Economic Situation and Prospects (WESP) 2017 Report (United Nations, 2017). Identification of the causative factors associated with flood-related, groundwater-borne enteric illness will aid development of evidence-based practises, policies and procedures to mitigate future public health risks.

\section{Methods}

\subsection{Literature identification, data sources, and searches}

The overarching review protocol has been adapted from several previous studies (Sargeant et al., 2006; Graham and Polizzotto, 2013; Hynds et al., 2014a). The developed primary research question guiding the review was:

What are the incidence, frequency, causative $\operatorname{organism}(\mathrm{s})$, and mechanism(s) associated with outbreaks of communicable/notifiable enteric infection caused by consumption of groundwater affected by surface water flooding in developed countries/regions?

Both Scopus and Web of Science databases were searched on June 22nd, 2017 (author LAA), with the Source-Pathway-ReceptorConsequence (SPRC) Model employed for search term development and literature identification (Fig. 1). The search was limited to papers in English and published from 1980 until present (Table 1). Literature scans employed Boolean positional operators ("AND", "OR", "SAME", "WITH", "ADJ") to appropriately refine literature identification, with supplementary legacy searches of article bibliographies $(n=12)$ and grey literature sources performed manually (LAA). Article inclusion required confirmation of infection via stool sampling, and/or confirmation of microbial groundwater contamination (faecal indicator organisms (FIO) or enteric pathogens) during or soon after a surface water flooding event. Epidemiological studies, whether descriptive or analytical, were considered eligible once a groundwater source directly contaminated by surface flooding was designated the primary source of enteric infection.

\subsection{Study selection}

As shown (Fig. 2; Identification), 4806 potentially appropriate articles were identified via the first (ID) review phase, decreasing to 3477 upon de-duplication (Fig. 2; Screening). The first phase of screening was undertaken via an assessment of article title, year, and abstract, and based upon developed eligibility criteria (Table 2), resulting in 112 articles going forward for eligibility assessment (Fig. 2; Eligibility). Full-texts were independently and concomitantly analysed by two researchers, again using developed inclusion/exclusion (eligibility) criteria. Abstracts without a full text (e.g. conference proceedings) were excluded at this stage. The primary inclusion criteria were: i) English-language articles only, ii) articles published after January 1st, 1980, iii) events occurring in high economies as defined in the WESP Report (United Nations, 2017), iv) groundwater-related outbreaks or groundwater source contamination triggered/caused by flooding events, v) groundwater consumption as the pathway of infection, vi) presence of post-event measurement of waterborne enteric pathogens (infection/contamination) or FIO (contamination), and vii) confirmed enteric waterborne illnesses in human population(s) (e.g. verotoxigenic E. coli (VTEC)/shiga-toxin producing E. coli (STEC), Cryptosporidium, Campylobacter, Salmonella, Giardia, norovirus, etc.).

Articles excluded during this phase were those that: i) reviewed results of previously published studies, ii) failed to establish a 


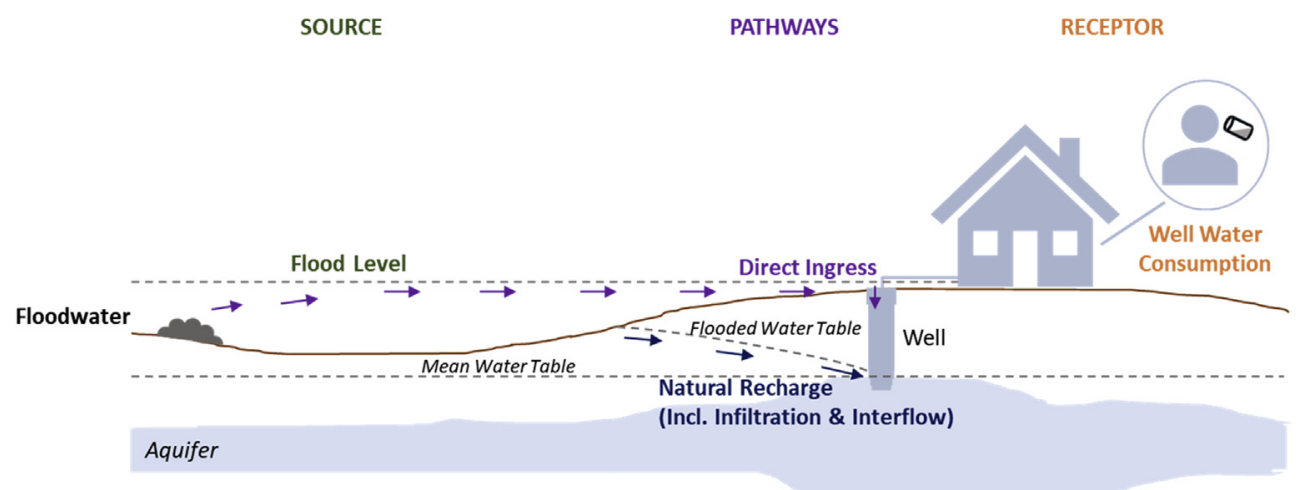

Fig. 1. Schematic of the connection between flood events (Source), groundwater contamination (pathways), and human exposure to contaminants (receptor).

Table 1

Search terms used in database search and correspondent classifications.

\begin{tabular}{ll}
\hline Term Classification & Search Terms \\
\hline Hazard & Flood, Rainfall, Storm, Contamination Source, Pluvial, Surge, Fluvial, Overland, Inundation, Surge \\
Pathway & Well, Borehole, Aquifer, Spring, Subsurface, Waterborne, Water-borne, Groundwater \\
Receptor/Consequence & Outbreak, Enteric, Sporadic, Gastroenteritis, AGI, Infection, Illness, Pathogen, Faecal, Epidemic \\
\hline
\end{tabular}

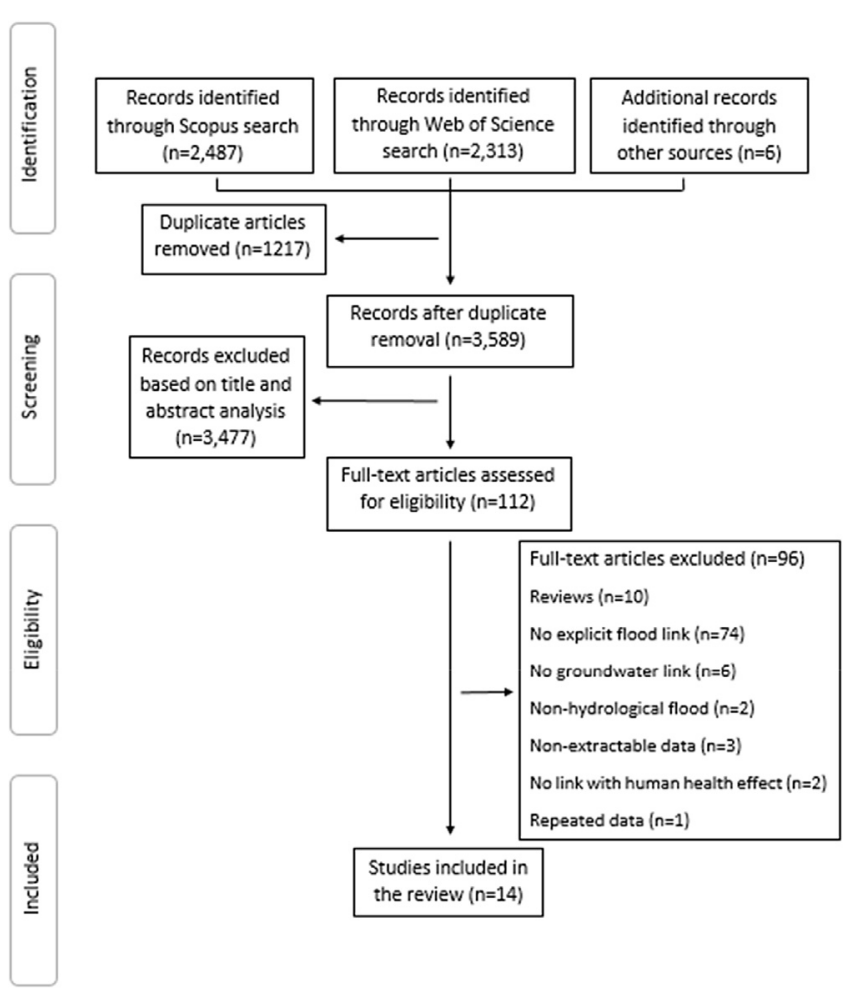

Fig. 2. Systematic review protocol employed during the current study including results of literature identification, screening, eligibility assessment, and final study inclusion.

causative/triggering link between surface flooding and contamination/outbreak events, iii) identified infection pathway as one other than direct groundwater consumption (primary cases), iv) provided a vague or indistinct description of the flooding event i.e. non-hydrological interpretation, v) presented unformatted and/or integrated event data which could not be extracted and/or discretised, vi) investigated groundwater not used for human consumption, and vii) reported surface flooding events previously studied by other included articles. Disagreements to eligibility were resolved via consensus among authors (LAA, PDH). In instances where data formatting and/or integration did not permit effective event-based extractions (e.g. flood-related outbreak data included within data from other non-flood related outbreaks), article authors were contacted at least three times over a 1-month period. In the absence of an author response after 1 month, papers were excluded (Exclusion Criteria v).

\subsection{Quality assessment}

Included papers were characterised by varying study designs, data reported, and overall objectives, thus in order to obtain comparable quality scores a single multi-disciplinary quality assessment tool was chosen, adapted from Mårtensson et al. (2016). Two researchers (LAA, PDH) independently rated the general research quality aspects for each included study, with all articles scoring $>70 \%$ and thus deemed 'Acceptable' for data extraction and synthesis.

\subsection{Data extraction}

All relevant data were extracted to, homogenised and verified within MS Excel 2016 spreadsheets. Data extractions were classified and exported under seven primary categories, namely, bibliographic details, study region (e.g. climate, settlement type, (hydro) geological setting, etc.), groundwater supply (e.g. type, historical water quality, susceptibility, depth, treatment(s) undertaken, use(s), etc.), flooding event (e.g. flood type, cause(s), intensity, etc.), contamination data (FIO/pathogen presence and type, analytical techniques, contamination source(s), confirmed ingress mechanisms, etc.), waterborne infection (outbreak types, analytical technique(s), numbers affected, attack rate, general practitioner (GP) visits and hospitalisation rates, crude incidence rates, symptomology, dose-response, etc.), and contamination/outbreak intervention(s) (type, success, time-lag, etc.). Articles were classified according to study design (i.e. outbreak (epidemiological) investigation or groundwater contamination study), while epidemiological studies were further categorised i.e. descriptive or analytical 
Table 2

Eligibility (inclusion/exclusion) criteria employed for literature screening.

\begin{tabular}{|c|c|}
\hline Inclusion Criteria & Exclusion Criteria \\
\hline Study Type: All research articles excluding reviews & Study Type: Academic Reviews \\
\hline Language: English & Language: non-English \\
\hline $\begin{array}{l}\text { Population: Groundwater systems (Public, Private, Community, non- } \\
\text { community, Mixed); Individuals, households or communities; High } \\
\text { income regions }\end{array}$ & $\begin{array}{l}\text { Population: Surface water bodies/watersheds, coastal/marine/estuarine } \\
\text { waterbodies, recreational water; Animals and vegetation; Low income regions } \\
\text { Exposure: Groundwater not-affected by floods; Surface water or other sources }\end{array}$ \\
\hline $\begin{array}{l}\text { Exposure: Flood-affected groundwater; Consumption of pathogens from } \\
\text { flood-contaminated groundwater }\end{array}$ & $\begin{array}{l}\text { affected by flood events; Human contact with flood-contaminated groundwater } \\
\text { other than consumption }\end{array}$ \\
\hline \multicolumn{2}{|l|}{ Comparator: Spatial and temporal controls } \\
\hline $\begin{array}{l}\text { Event/Outcome: Drinking-groundwater contaminated with enteric } \\
\text { pathogens; Groundwater-borne enteric outbreaks }\end{array}$ & $\begin{array}{l}\text { Event/Outcome: Contamination of a groundwater source not used for drinking; } \\
\text { Drinking source other than groundwater (i.e. surface water) as pathway for human } \\
\text { infection }\end{array}$ \\
\hline \multicolumn{2}{|l|}{ Study design: Epidemiological, environmental, and social studies } \\
\hline Period: 1980 - present & Period: pre-1980 \\
\hline
\end{tabular}

study. Several variables were not explicitly documented within all studies, in which case study authors were contacted for clarification and/or articles were analysed for identifiable characteristics, and thus classified. This was the case for flood type (fluvial, pluvial or coastal), settlement type (urban, rural, industrial, or mixed) and supply end-user (domestic, industrial, tourism, transient, mixed), source susceptibility (high, moderate, low), and the occurrence of secondary cases of infection. Groundwater system type (private/ public) was categorised based on explicit classification within the study description, when available. Groundwater contamination ingress mechanisms when described were categorized based upon definitions provided by Lee (2005) and Hynds et al. (2012), namely, i) direct surface water ingress: contaminated surface water directly enters and contaminates groundwater systems via the constructed source, ii) groundwater recharge: contaminated surface water enters and contaminates groundwater systems via geological pathways, or through pore spaces in the soil matrix, iii) direct migration: contaminants migrate into the groundwater from below ground sources (e.g. storage tanks and pipelines) within the saturated zone, and, iv) inter-aquifer exchange: contaminated groundwater mixes with uncontaminated groundwater through hydraulic communication. Finally, contamination/outbreak interventions, when undertaken, were classified as being "effective"/ "ineffective" based upon explicit reporting, or in the absence of the latter, when the time elapsed between outbreak initiation and the associated intervention was greater than the time between an intervention and conclusion of the outbreak. A total of 97 variables were extracted by one reviewer into a standardized form, followed by verification and homogenisation by a second reviewer. Initial intentions were to perform a meta-analysis, however, this was not possible due to lack of standardised reporting amid included papers, i.e. very few variables consistently reported by $>10$ articles.

\section{Results}

\subsection{Included studies}

Upon completion of the review process, 14 articles were included for data extraction and analysis (Table 3), including 12 studies from online database searches, and an additional two identified via manual search. As shown (Table 3), aside from one study undertaken in New Zealand (Jack et al., 2013), all other included papers derived from Europe $(\mathrm{n}=8)$ and North America $(n=5)$. Studies spanned a 25-year period (1982-2017), with 2013 the only year during which more than one study was published (Bradbury et al., 2013; Jack et al., 2013). All studies adhered with the primary inclusion criteria insofar as they reported a hydrological flooding event as the primary cause/trigger for contamination of groundwater drinking supplies; three studies (21.5\%) focused solely on flood-triggered contamination of groundwater sources, while the remaining 11 articles comprised a descriptive or analytical epidemiological investigation. Three epidemiological articles described multiple groundwater-borne outbreaks, of which at least one was flood-related. All articles included some form of environmental investigation in their study design (i.e. groundwater sampling and analysis), albeit to varying degrees.

\subsubsection{Study regions}

Overall, $64 \%(n=9)$ of studies were focused in categorically rural areas, $22 \%(n=3)$ in urban, and the remaining $14 \%(n=2)$ in "mixed settlements" i.e. discontinuous urban fringe or peri-urban regions. Overall, 12 of the 14 studies included an assessment of surface water body (SWB) presence in the region as a component of their environmental investigation, with adjacent SWBs identified in 11 of these, including rivers ( $7 / 11)$, lakes $(2 / 11)$, creeks $(2 / 11)$, and a dike (1/11). Similarly, as part of reported environmental investigations, $79 \%(n=11)$ of the 14 studies identified possible sources of contamination found in the vicinity, with $64 \%$ highlighting human waste (e.g. septic tanks and untreated sewage), and $36 \%(n=4)$ naming animal sources. SWBs comprised a likely contaminant pathway in 5 of the 11 studies wherein they were present (45\%). There was a notable paucity of data describing the geological characteristics of study regions (e.g. aquifer type, bedrock geology, hydraulic conductivity, subsoil type, depth, and permeability), with geological setting described in just $43 \%(n=6)$ of articles, of which $50 \%$ (3/6) took place in regions dominated by alluvial aquifers, two (33\%) were located in potentially fractured sandstone and the remaining study covered a karstic (Carboniferous limestone) area.

\subsection{Groundwater supplies}

As shown (Table 3), 10 of 14 included studies were associated with a public groundwater supply, whilst the remaining four were private sources (Table 3). In all, eleven studies referred to wells, two were groundwater spring sources, and one concurrently reported on both wells and springs, adding that only the well was affected by flooding event (Dura et al., 2010). Supplied consumers (reported in 93\% of articles) were primarily domestic households and commercial/industrial users (12/13-92\%). Half of the included studies $(n=7)$ comprised historical (i.e. longitudinal sampling prior to flooding event) groundwater quality data, six of which reported good or satisfactory pre-event water quality i.e. compliance with water quality guidelines. In 5 of 7 cases, studies adjudged water quality based upon the presence/absence of FIO, namely total $\mathrm{Co}^{-}$ liforms (TC) (4/5), and E. coli (2/5), whilst in the two remaining studies parameters used were not specified. Sixty four percent $(9 /$ 
Table 3

Primary descriptive characteristics of included studies $(n=14)$.

\begin{tabular}{|c|c|c|c|c|c|c|c|c|c|}
\hline Study & Year & Country & $\begin{array}{l}\text { Study } \\
\text { Type }\end{array}$ & $\begin{array}{l}\text { Settlement } \\
\text { Type }\end{array}$ & $\begin{array}{l}\text { Supply } \\
\text { Type }\end{array}$ & $\begin{array}{l}\text { GW } \\
\text { Source(s) }\end{array}$ & $\begin{array}{l}\text { Source Susceptibility } \\
\text { to Contamination }\end{array}$ & $\begin{array}{l}\text { Historical } \\
\text { GW quality }\end{array}$ & $\begin{array}{l}\text { Treatment } \\
\text { Type }\end{array}$ \\
\hline Beaudeau et al. (1) & 2008 & France & Outbreak & Rural & - & Well & - & - & Chlorination $^{\mathrm{a}}$ \\
\hline Borchardt et al. (2) & 2004 & USA & Contam. & Urban & Public & Wells & High & - & Chlorination \\
\hline Bradbury et al. (3) & 2013 & USA & Contam. & Urban & Public & Wells & High & Good & Chlorination \\
\hline Bridgman et al. (4) & 1995 & England & Outbreak & Mixed & Public & Wells & Very High & Satisfactory & Chlorination \\
\hline Cannon et al. (5) & 1991 & USA & Outbreak & Rural & Private & Wells & - & - & Ultraviolet \\
\hline Dura et al. (6) & 2010 & Hungary & Outbreak & Urban & Public & Wells \& Springs & High & Mostly Good & Chlorination \\
\hline Eccles et al. (7) & 2017 & Canada & Contam. & Mixed & Private & Wells & Moderate/High & Good & Not Reported \\
\hline Galbraith et al. (8) & 1987 & England & Outbreak & Rural & Private & Spring & - & - & Chlorination $^{\mathrm{a}}$ \\
\hline Goodman et al. (9) & 1982 & USA & Outbreak & Rural & Public & Wells & - & - & None \\
\hline Hannienen et al. (10) & 2003 & Finland & Outbreak & Rural & Public & Wells & High & - & None \\
\hline Howe et al. (11) & 2002 & England & Outbreak & Rural & Public & Spring & High & Good & Chlorination \\
\hline Jack et al. (12) & 2013 & New Zealand & Outbreak & Rural & Private & Well & High & Poor & Chlorination \\
\hline Kukkula et al. (13) & 1997 & Finland & Outbreak & Rural & Public & Well & High & Good & None \\
\hline Mouly et al. (14) & 2015 & France & Outbreak & Rural & - & Wells & - & - & Chlorination $^{\mathrm{a}}$ \\
\hline
\end{tabular}

Note: a - Damaged by flooding.

14) of studies included some level of susceptibility assessment, with all these implying likely high or extreme groundwater susceptibility to contamination (Table 4 ). Just 4 studies reported supply depth, of which two described "shallow" wells $(<15.2 \mathrm{~m})$. Similarly, only 4 articles comprised an assessment of the supply (well or spring) condition, all, 1 private and 3 public supplies, were considered in poor condition and/or maintenance was lacking (e.g. absence of operational well liner, lack of an appropriate protection zone, evident structural damage, etc.). The majority of articles (13/ 14) reported on treatment system absence/presence; $72 \%(n=10)$ reported that treatment was present, namely chlorination $(9 / 10)$ and UV treatment (1/10), while three (Goodman et al., 1982; Kukkula et al., 1997; Hänninen et al., 2003) reported that treatment was not employed, all of which were public (municipal) supplies.

\subsection{Surface water flooding and groundwater contamination}

There were no reports within the reviewed literature on groundwater contamination due to coastal (surge) flooding (Table 4); $57 \%(n=8)$ of reports portrayed pluvial flooding events leading to groundwater contamination, $36 \%(n=5)$ referred to fluvial events, and one article (Jack et al., 2013) did not explicitly state flood characteristics including the flooding mechanism. High intensity, low return period precipitation events represented the primary causative factor in $10 / 13(77 \%)$ reports, $2 / 13$ (15\%) were caused by snowmelt, while the remaining event $(1 / 13)$ occurred as a result of heavy snowfall (in the absence of significant snowmelt). Flood intensity was only explicitly stated in $28 \%(4 / 14)$ of articles, of which $75 \%(n=3)$ classified it as severe. The direct effects of flooding events on groundwater quality were elucidated in $86 \%$ $(\mathrm{n}=12)$ of cases, with the predominant impacts being (rapid) exposure to contaminated surface/flood waters (10/12-83\%) and damage to water chlorination systems (2/12-17\%). Only 4 articles (28\%), all of which were epidemiological studies, reported changes in groundwater's organoleptic characteristics post-flooding event, with $3 / 4(75 \%)$ of these reporting notable turbidity changes $0-11$ days (mean $=5.3$ days) prior to outbreak initiation.

All included papers incorporated some form of post-flooding groundwater quality sampling and analysis, either directly from groundwater sources, or indirectly via network sampling. Proof of contaminant ingress was found in all cases. Only two studies (14\%), both classified as being 'groundwater contamination' papers (i.e. focusing on groundwater quality as opposed to human outbreak investigations) (Borchardt et al., 2004; Bradbury et al., 2013) performed "pre-treatment" sampling only. Groundwater samples were directly analysed for enteric pathogens in 10 of the 14 studies; $80 \%$ of these $(n=8)$ found evidence of at least one enteric pathogen, as follows: viruses (e.g. norovirus, enterovirus, rotavirus, hepatitis A virus) (5/8-62\%), bacteria (Campylobacter spp.) (2/8-25\%), and protozoa (Giardia spp., Cryptosporidium spp.) (2/8-25\%), the four remaining studies did not investigate pathogen presence/absence. Just over half of those studies which reported on the presence of an enteric pathogen (5/8) specified the pathogen sero/genotype. As might be expected, studies reporting on pre-treatment or nontreated groundwater's found higher levels of pathogen concentration and diversity. Overall 11 studies tested for the presence of at least one FIO, with $91 \%(n=10)$ reporting that FIOs were present. No evidence of FIOs were found by Borchardt et al. (2004), and they hypothesize that recharge/infiltration through alluvial sediments likely removed the majority of microbial contaminants via natural attenuation or biodegradation. Among the 10 studies that reported FIO presence, 7 encountered E. coli, 7 found (total and/or faecal) coliforms, 3 enumerated Enterococci, and 1 study reported positive heterotrophic plate counts (HPC). Four studies (Borchardt et al., 2004; Bridgman et al., 1995; Dura et al., 2010; Eccles et al., 2017) analysed "pre-event" samples or accessed historical pre-flooding sample analysis, with three of these reporting an absence of preevent contamination (FIO and/or enteric pathogens), while the remaining study (Eccles et al., 2017) stated that microbial contaminants had been present prior to flooding, albeit contaminants were present in higher concentrations post-flooding.

Five of the 11 studies (45\%) that reported SWB presence carried on sampling and analysis for enteric pathogens (5/5) and FIO presence $(4 / 5)$ in them. All reported the presence of enteric pathogens and/or faecal bacteria. Groundwater contamination mechanisms triggered by flooding events were identified in $50 \%(n=7)$ of studies included in the review, as follows: direct (rapid) ingress of contaminated flood waters (3/7), groundwater recharge $(3 / 7)$, and direct migration (1/7) (Table 4$)$. Of the 14 studies, 11 identified a probable contamination source: $54 \%(n=6)$ were of human origin, $36 \%(n=4)$ were of animal origin, and $9 \%(n=1)$ were a combination of both. Eight studies reported on diffuse contaminant sources, 1 study provided evidence of a point source and the remaining papers $(n=2)$ reported a "combined" (i.e. point and diffuse) source of contamination.

Just one study explicitly reported a statistical link between the investigated flooding event and groundwater contamination, namely Eccles et al. (2017), a “groundwater contamination' study (Table 3). Eccles et al. (2017) present a statistical comparison between historical groundwater $E$. coli and TC concentrations from the years 2005-2013 inclusive; results indicate that concentrations 


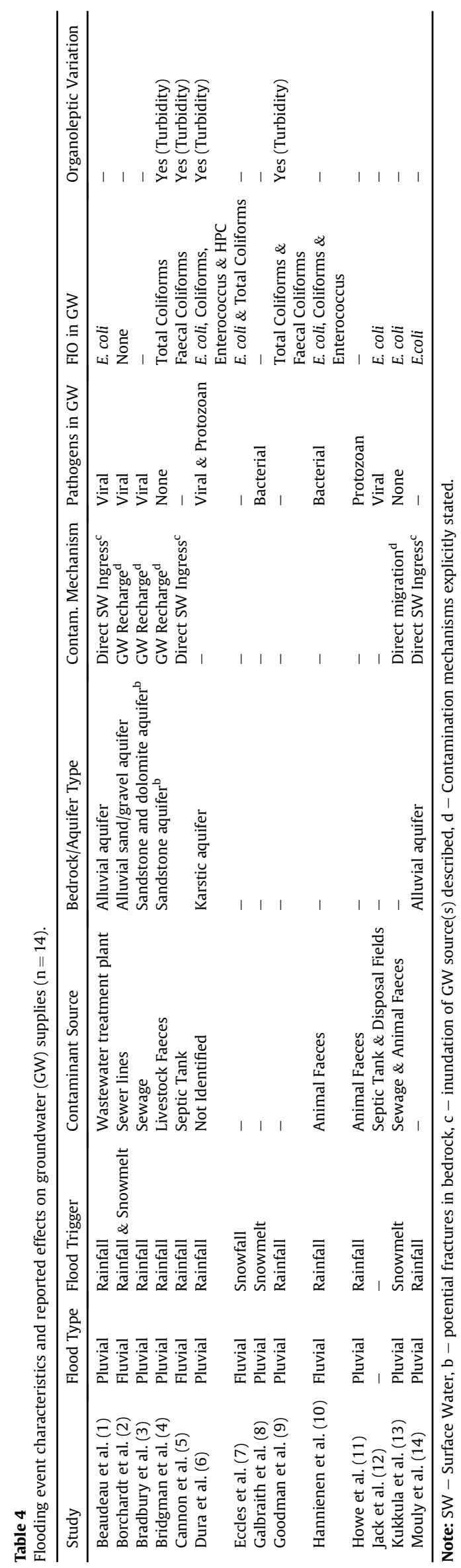

during 2013, when large a scale flooding event occurred, were statistically higher than the 8 previous years, apart from 2005, when a large flooding event also occurred.

\subsection{Flood-related human enteric infection}

Waterborne outbreaks of enteric illness were investigated in 11 of the included papers (79\%) (Table 5), with infection clusters distributed across all seasons, albeit with a slightly higher incidence during spring and autumn, as follows: summer (18\%), spring (37\%), winter (18\%), and autumn (27\%). Overall, $91 \%(n=10)$ of epidemiological studies reported on a propagated, single-source waterborne outbreak, with the remaining study (Galbraith et al., 1987) not presenting adequate information to classify or infer epidemic type. An outbreak duration pertaining to all (primary and secondary) cases of infection was reported in $72 \%(n=8)$ of cases and ranged from 11 to 84 days (mean $=31.6$ days), while the outbreak duration associated with solely primary cases was present in just three studies, ranging from 5 to 56 days (mean $=26.7$ days). Two epidemiological studies failed to report an outbreak duration (Cannon et al., 1991; Beaudeau et al., 2008), while 5 articles (45\%) comprised outbreak curves. Three studies stated the proportion of secondary cases; these varied from 9 to $21.3 \%$ (mean $=14.1 \%$ ). Four articles comprised an (estimated) outbreak lag period i.e. the time (days) between initiation of a flood event and the first case of infection (Fig. 3), ranging from 1 to 28 days (mean $=7.4$ days), with no association found between time-lag and pathogen type, flood type, and aquifer type. The period between the first case of infection and the outbreak peak represented a mean of $30 \%$ of total outbreak duration (Min: 17\%, Max: 47\%), calculated from four studies, wherein both variables were reported.

The majority of studies (10/11) comprised patient stool sampling (i.e. case confirmation); sampling descriptions, from 5 manuscripts, showed a mean of 128 stool analysed samples per study (Min: 8; Max: 521). Enteric infection was positively confirmed in all studies that undertook stool sampling, as follows: norovirus $(6 / 10)$, Campylobacter (3/10), Cryptosporidium (2/10), Yersinia (1/10), adenovirus (1/10), and rotavirus (1/10), with more than one pathogen (i.e. co-infection) detected in the course of two investigations. Five studies effectively "closed the epidemiological loop", insofar as they established that groundwater sources were positive for enteric pathogens, in concurrence with stool sample analysis, thus providing evidence that the same pathogen(s) was present in both human and environmental samples. These were norovirus (3/5), Campylobacter (1/5), and Cryptosporidium (1/5) (Beaudeau et al., 2008; Dura et al., 2010; Hänninen et al., 2003; Howe et al., 2002; Jack et al., 2013). Three articles presented evidence of a positive dose-response relationship (Beaudeau et al., 2008; Bridgman et al., 1995; Cannon et al., 1991). Just five studies (45\%) established a statistical link between groundwater contamination and the occurrence of waterborne infection (Beaudeau et al., 2008; Bridgman et al., 1995; Cannon et al., 1991; Goodman et al., 1982). Three of the epidemiological articles comprised a retrospective cohort study, of which two studies presented calculated relative risks (RR) for groundwater exposure e.g. persons living inside outbreak catchment areas versus persons living outside outbreak catchment area, both of which were highly significant ( $>7.5$ in both cases). Similarly, a case-control study by Bridgman et al. (1995) reported an odds ratio of $4.8-28.2$, depending on consumption rate.

Case (surveillance) interviews were undertaken in 6 of 11 studies, 3 of which (50\%) explored other possible (non-groundwater related) sources of contamination (e.g. food, animal contact, etc.). Explicit case definitions were provided in 8 of the 11 healthrelated articles and were found to vary considerably. Confirmed 


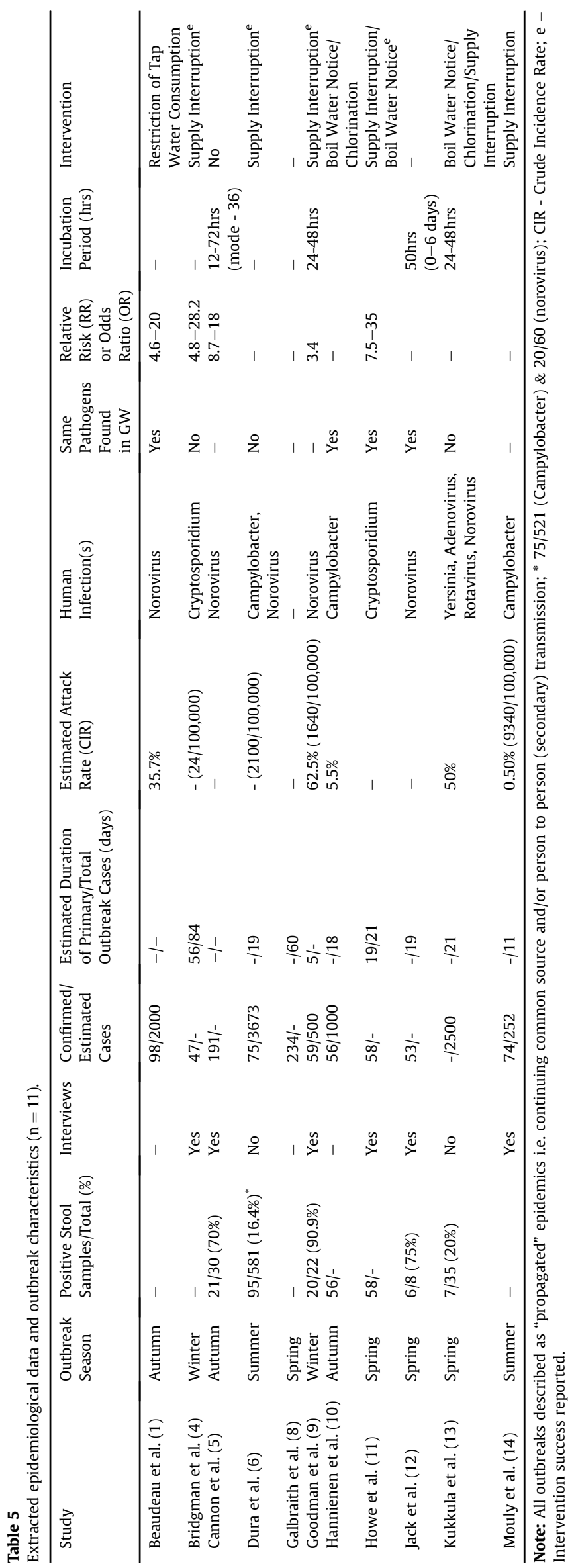

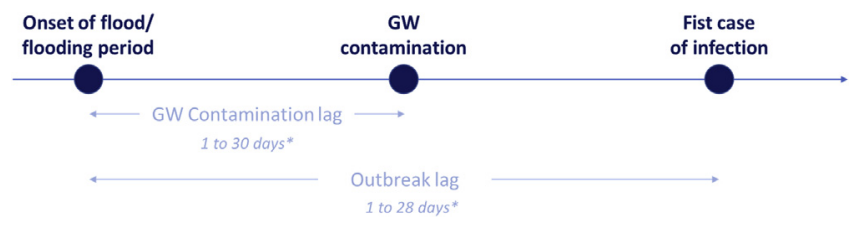

Fig. 3. Timeline connecting flood event, groundwater contamination, and human infection. *Data acquired from studies identified and included in current review.

cases, reported in all but one outbreak paper (Kukkula et al., 1997), ranged from 47 to 191 (mean $=94$ cases per outbreak), with confirmed attack rates, reported in $45 \%(n=5)$ of articles, ranging from 0.1 to $63 \%($ mean $=35.4 \%)$ ). Estimates pertaining to potential/ suspected infection rates were presented in five articles, with a mean confirmed infection rate of $27.3 \%$ (ranging from 0.5 to $62.5 \%$ ). Case estimates were reported for six waterborne outbreaks; in all, there were 954 confirmed cases (Mean 95 cases/outbreak) and 9925 suspected cases (Mean 1654 cases/outbreak), equating to a case ratio of 19.8 suspected cases per confirmed case (3.4-49).

A mean epidemic crude incidence rate of 32.8 cases/1000 residents was calculated from data presented in four studies (Min: 0.24/1000, Max: 93.4/1000). Vulnerable sub-populations were explicitly identified and examined in four (36.4\%) of the study reports; these were defined as $<5$ years (50\%), $6-14$ years ( $25 \%)$, and 78-87 years (25\%). Only one study reported a significant gender imbalance pertaining to infection likelihood (Mouly et al., 2016), presenting a female/male infection ratio of 1.6 (campylobacteriosis). Symptomology was outlined in 64\% (7/11) of studies with diarrhoea $(n=7)$, fever $(n=6)$, vomiting $(n=5)$, abdominal pain $(n=5)$, nausea $(\mathrm{n}=4)$, and headaches $(\mathrm{n}=3)$, as the most frequently identified symptoms of enteric infection. A mean incubation period of $41 \mathrm{~h}$ was found among 4 studies, ranging from 12 to $72 \mathrm{~h}$, with an associated mean duration of symptomatic illness equating to 3.5 days (Min: 1.5 days, Max: 30 days) $(n=5)$. Hospitalization rates ranged from 3 to $11 \%($ mean $=6.1 \%)(n=3)$, while GP visit rates of $30 \%$ and $38.5 \%$ were presented in two studies.

Epidemiological interventions were outlined in 8 of the 11 health-specific articles (Table 5), as follows: i) interruption of the contaminated supply $(6 / 8,75 \%)$, ii) boil water notice $(3 / 8,38 \%)$, shock chlorination $(2 / 8,25 \%)$, and iii) water consumption restrictions in the absence of supply interruption $(1 / 8,12 \%)$. The mean time elapsed between outbreak initiation and the introduction of an intervention was 11 days, ranging from 1 to 30 days $(n=5)$, and equating to approximately $61 \%$ of the mean outbreak length $(54-68 \%)(n=3)$. Based upon article reporting, all study interventions were successful insofar as they halted an upsurge in outbreak-related cases, with all clusters eventually brought under control.

\section{Discussion and conclusions}

In light of concerns regarding climate change and associated global effects, namely, predicted increases in flooding event frequency and intensity, the infrastructural and economic consequences of flooding events have received significant attention. Conversely, the physical human health effects of these events, and particularly, the effects of (private and municipal) flood-triggered enteric microbial groundwater contamination, remains underreported and poorly understood. As such, a literature identification protocol was developed and employed to identify, assess and synthesize all relevant data within the peer-reviewed research literature pertaining to the nexus between surface water flooding, groundwater contamination by enteric pathogens, and acute 
gastrointestinal infection (AGI) among affected communities. Studies were limited to high-income countries, characterised by similar groundwater-related practices (Zektser and Everett, 2004), to ensure comparability. The authors consider that reported findings offer valuable insights into the importance of this publichealth related issue, and highlight the need for more comprehensive research on the topic, and subsequent development of appropriate policy and health surveillance strategies, in addition to groundwater monitoring and remediation, for what will likely represent an increasingly significant human health burden.

Just fourteen relevant studies were identified over the 37-year review period via a comprehensive review process (Table 2); these were found to differ significantly in terms of study type and data reporting procedures, thus a tangible meta-analysis was not possible. While the low number of identified studies represents a limitation, this also denotes a primary study finding, insofar as there is currently a significant paucity of information within the published literature pertaining to the nexus between flooding events, groundwater contamination and human enteric illness. Myriad previous studies have examined human AGIs caused by consumption of contaminated groundwater (Wallender et al., 2014; Hynds et al., 2014b; Murphy et al., 2017), climate-triggered groundwater contamination (O'Dwyer et al., 2016; Uejio et al., 2017), and the occurrence and frequency of surface water flooding (Ten Veldhuis et al., 2010; De Man et al., 2014). The role of precipitation in the mobilisation of pathogens within the environment has been particularly well substantiated. Rainfall influences the vertical and horizontal movement of pathogens at the soil interface which moderates the rate and concentration at which pathogens may enter source water and/or drinking water supplies (Unc and Goss, 2003). Heavy "flash" rainfall and periods of prolonged rainfall have been shown to increase runoff from agriculture, transporting microbiologically diverse materials (surface runoff, associated sediments and faecal matter) into rivers, coastal waters, and groundwater wells (Semenza and Menne, 2009). The increased mobility of pathogenic microbiota enhances human susceptibility to disease, particularly when in contact with contaminated (and untreated) drinking water sources. For example, O'Dwyer et al. (2016) report that waterborne verotoxigenic E. coli outbreaks in the Republic of Ireland were statistically associated with both persistent and heavy antecedent rainfall. Compounding the impact of rainfall on pathogen mobility, periods of flooding can create vast areas of standing water which unfolds new concerns for potential pathogen exposure and may exasperate contamination ingress to both surface and groundwater sources. In Europe, flooding has been specifically associated with an increased risk of waterborne disease outbreaks in the UK (Reacher et al., 2004) Finland (Miettinen et al., 2001), Sweden (Ebi, 2006) and the Czech Republic (Kríz et al., 1998). However, as evidenced in the current study, few studies have sought to appropriately relate all three components through the lens of the "Hazard-Pathway-Receptor" model of environmental contamination or the "Epidemiological Triad".

Notwithstanding the low number of relevant articles identified within the published literature, some preliminary trends and biases could be identified. For example, $75 \%(n=8)$ of studies which explicitly categorised the groundwater supply focused on public (municipal) supplies; while this is epidemiologically explicable (i.e. public supplies associated with larger outbreaks of infection), it does not align with existing knowledge which has demonstrated that private well users are at higher risk of infection due to a lack of legislation and inadequate or absent water treatment (Hynds et al., 2012; O'Dwyer et al., 2014). As such, this suggests the existence of a "research bias", both in terms of supply type, and more worryingly from a human health perspective, the effects of flooding events on sporadic and endemic rates of enteric infection. Most private groundwater sources are located in rural areas characterised by a ubiquity of human and animal contaminant sources, with many remaining unregulated in terms of design, location, treatment, and maintenance, and associated with low levels of consumer and institutional awareness (Hynds et al., 2013; Murphy et al., 2017). Another frequently encountered characteristic of included studies was a paucity of direct pathogen analysis of both groundwater and associated surface (flood) waters, thus preventing confirmation of the causative link between flood-triggered groundwater contamination and adverse human health outcomes. Within the published literature, just one study was identified which sought to explicitly analyse the effects of a significant flooding event on local groundwater quality (Eccles et al., 2017). All remaining studies were typified by a significantly lower level of prominence being ascribed to accurately describing flooding events and the mechanistic associations between surface water flooding and groundwater contamination. For example, explicit flood classification (e.g. fluvial, pluvial, surge/coastal, etc.) and associated characteristics (e.g. duration, intensity, height, etc.) were entirely absent in the majority of included papers, while mechanisms by which flooding events were causative of groundwater contamination were typically inferred rather than explicitly proven. Notably, a number of prominent studies excluded from the current review did not make any distinction between heavy/extreme rainfall and the explicit presence of surface water flooding (e.g. Risebro et al., 2007; Wallender et al., 2014). In undertaking the review process, the authors note that the lack of a clear division between these two contamination triggers occurs frequently within the literature, and particularly within epidemiological/public health studies.

The majority of reported aquifer types were high permeability and/or of karstic, and thus, direct ingress was a frequently reported contamination mechanism (3/7 studies). These hydrogeological settings are typically indicative of rapid subsurface pathways (Lee, 2005), and consequently, bypass of the natural attenuative processes afforded by the unsaturated zone. Previous work has shown that karst areas typically exhibit significantly higher levels of microbiological contamination (Bradley et al., 2015), thus reflecting the inherently vulnerable nature of these dynamic flow systems, in concurrence with the lack of attenuation capacity associated with shallow (or absent) soils and subsoils (Pronk et al., 2009). This is particularly the case regarding diffuse (non-point) contamination, which is associated with flooding events (Drew et al., 1996; Wallender et al., 2014). As such, future studies should seek to report geomorphic, hydrogeological, and source (well)-specific data (e.g. topography, aquifer type, bedrock conditions, flood type, flood source, well condition/maintenance, etc.), as these characteristics directly affect groundwater contamination lag (i.e. time between flood initiation and aquifer/well contamination), outbreak lag (i.e. period (time-lag) between flooding and primary infection) (Fig. 3) and microbiological load. Failures to accurately investigate and/or report on the contamination pathway prevents i) clear elucidation of contamination and/or outbreak pathways, ii) definitive evidence-based interventions, and iii) informed flood management planning to ensure appropriate environmental health protection of current and future generations of groundwater users.

The concurrence between settlement patterns, public/municipal infrastructure, and groundwater/surface water usage in coastal/estuarine regions and large river floodplains may explain why outbreak reports triggered by pluvial flooding surpassed that of fluvial flooding events, while events caused by coastal storm surges were not encountered at all within the literature. However due to the small sample size, definite conclusions cannot be reached, and the authors recommend that further work be focused on the apparent inequality between location (i.e. hydrological 
setting) and the instance of flood-triggered groundwater-borne enteric infection.

There was a marked seasonal distribution with regard to floodrelated outbreaks of enteric infection (Table 1), with infection clusters shown to occur in all seasons. Accordingly, more work is required in order to establish hydrological, microbial (pathogen lifecycle), and contaminant source characteristics and their periodic contributions, thus permitting appropriate microbial risk assessment and timely, locally-specific mitigation strategies. Based upon extracted data, approximately 945 confirmed cases of flood-related enteric disease were examined across 10 epidemiological studies, however, these concurred with almost 10,000 suspected cases, equating to approximately 20 suspected cases per confirmed case. As such, it is immediately apparent that at present, there are no national or global estimates available for the human gastrointestinal health burden of flood-related groundwater contamination.

Based upon the reviewed literature, all papers that compared pre- and post-flooding water quality reported higher FIO concentrations after flooding $(n=4)$, thus little doubt remains as to the public health significance of flooding events among individuals and communities served by groundwater supplies. However, public health experts cannot be expected to have a deep understanding of hydro (geo)logical concepts and models, and thus appropriately identify flood-related parameters and mechanisms during outbreak investigations and surveillance activities. Likewise, hydro (geo)logists are not equipped to evaluate public health responses to contamination events. Moreover, neither of these disciplines are qualified to understand the social aspects which need to be considered to effectively communicate hydrological risks or design appropriate community interventions. Historically, flood management strategies have focused on floodwater control, whereas contemporary approaches are and must continue to shift towards increasingly multi-faceted methods (O'Neill, 2017). Effective integration of knowledge, methodologies and theories across a broad base of disciplines including hydrology, hydrogeology, epidemiology, and the social sciences is, therefore, imperative to permit for development of comprehensive mixed-methods studies that address the complexities associated with the public health impacts of flood events.

Perhaps the greatest challenge in public health-related hydrogeological assessments is not sufficiently addressed within the literature, the concurrent issues of hydro (geo)logical time lag and enteric infection latency. Following a flood event, and consequent consumption of contaminated groundwater, symptomatic infection may not present itself for several days (Fig. 3). For example, while a 12- to 36-h incubation period is associated with salmonellosis, campylobacteriosis typically does not manifest for 3-5 days postinfection (Horn and Lake, 2013), while VTEC infection is associated with an incubation period from anything to 3 to 8 days (Karmali et al., 2010). This time lag is further increased by outbreak notification delays, which are typically not declared until multiple spatially-specific cases are reported to public health authorities. Consequently, when hydrogeological investigations and subsequent groundwater sampling is undertaken in response to cases of infection, multiple days, if not weeks, have already passed and contamination may be decreased or entirely absent. As such, in order to effectively monitor and mitigate groundwater related infection, periodic sampling and continual assessment should to be undertaken, particularly in flood prone, high groundwater reliant areas. While continuous monitoring of bacterial contamination may not be practicable, parameters such as turbidity, electrical conductivity, and watertable depth have been shown to represent effective indicators of significant shifts in groundwater microbial quality and groundwater/surface water interactions (Glassmeyer et al., 2005; Katz et al., 2009), and may be easily and inexpensively monitored at the local level using subsurface probes, thus providing an early warning mechanism and prompting more specific analyses when required.

Due to the demonstrable public health significance of impacts arising from increased groundwater susceptibility, and further exacerbation by climate change, strategies to increase awareness about potential sources of contamination and to motivate precautionary behaviour (e.g. drinking water testing and treatment) are necessary. Mainstreaming climate adaptation concerns into planning policies will also be necessary, particularly in rural areas, to reduce human exposure to waterborne sources of enteric infection.

\section{Acknowledgements}

The authors wish to thank Irish Research Council (IRC) and Geological Survey of Ireland (GSI) for providing research funding for this project under the remit of their Research for Policy and Society Programme 2016.

\section{Appendix A. Supplementary data}

Supplementary data related to this article can be found at https://doi.org/10.1016/j.envpol.2018.01.104.

\section{References}

Arnell, N.W., Gosling, S.N., 2016. The impacts of climate change on river flood risk at the global scale. Climatic Change 134 (3), 387-401.

Barredo, J.I., 2007. Major flood disasters in Europe: 1950-2005. Nat. Hazards 42 (1), $125-148$.

Bradley, C., Byrne, C., Craig, M., Free, G., Gallagher, T., Kennedy, B., McDermott, G., 2015. Water Quality in Ireland 2010-2012. Environmental Protection Agency Wexford, Ireland. Available at: http://www.epa.ie/pubs/reports/water/ waterqua/wqr20102012/\#. . (Accessed 16 January 2017).

Beaudeau, P., de Valk, H., Vaillant, V., Mannschott, C., Tillier, C., Mouly, D. Ledrans, M., 2008. Lessons learned from ten investigations of waterborne gastroenteritis outbreaks, France, 1998-2006. J. Water Health 6 (4), 491-503.

Borchardt, M.A., Haas, N.L., Hunt, R.J., 2004. Vulnerability of drinking-water wells in La Crosse, Wisconsin, to enteric-virus contamination from surface water contributions. Appl. Environ. Microbiol. 70 (10), 5937-5946.

Bradbury, K.R., Borchardt, M.A., Gotkowitz, M., Spencer, S.K., Zhu, J., Hunt, R.J., 2013. Source and transport of human enteric viruses in deep municipal water supply wells. Environ. Sci. Technol. 47 (9), 4096-4103.

Bridgman, S.A., Robertson, R.M.P., Syed, Q., Speed, N., Andrews, N., Hunter, P.R., 1995. Outbreak of cryptosporidiosis associated with a disinfected groundwater supply. Epidemiol. Infect. 115 (3), 555-566.

Cannon, R.O., Poliner, J.R., Hirschhorn, R.B., Rodeheaver, D.C., Silverman, P.R. Brown, E.A., Glass, R.I., 1991. A multistate outbreak of Norwalk virus gastroenteritis associated with consumption of commercial ice. J. Infect. Diseases 164 (5), 860-863.

Charrois, J.W., 2010. Private drinking water supplies: challenges for public health Can. Med. Assoc. J. 182 (10), 1061-1064.

Curriero, F.C., Patz, J., Rose, B., Lele, S., 2001. The association between extreme precipitation and waterborne disease outbreaks in the United States, 1948-1994. Am. J. Publ. Health 91 (8), 1194-1199.

De Man, H., Van Den Berg, H.H., Leenen, E.J., Schijven, J.F., Schets, F.M., Van der Vliet, J.C., de Roda Husman, A.M., 2014. Quantitative assessment of infection risk from exposure to waterborne pathogens in urban floodwater. Water Res. 48, 90-99.

Devitt, C., O'Neill, E., 2017. The framing of two major flood episodes in the Irish print news media; implications for societal adaptation to living with flood risk. Publ. Understand. Sci. 26 (7), 872-888.

Drew, D., Burke, A., Daly, D., 1996. Assessing the extent and degree of karstification in Ireland. In: Proceedings of International Conference on Karst Fractured Aquifers-vulnerability and Sustainability. University of Silesia, KatowiceUstron, Poland, pp. 37-47.

Dura, G., Pándics, T., Kádár, M., Krisztalovics, K., Kiss, Z., Bodnár, J., Papp, E., 2010. Environmental health aspects of drinking water-borne outbreak due to karst flooding: case study. J. Water Health 8 (3), 513-520.

Ebi, K.L., 2006. Floods and human health. In: Menne, B., Ebi, K. (Eds.), Climate Change and Adaptation Strategies for Human Health. Steinkopff, Darmstadt pp. 131-156.

Eccles, K.M., Checkley, S., Sjogren, D., Barkema, H.W., Bertazzon, S., 2017. Lessons learned from the 2013 Calgary flood: assessing risk of drinking water well contamination. Appl. Geogr. 80, 78-85. 
Engström, E., Mörtberg, U., Karlström, A., Mangold, M., 2017. Applying spatial regression to evaluate risk factors for microbiological contamination of urban groundwater sources in Juba, South Sudan. Hydrogeol. J. 25 (4), 1077-1091.

Galbraith, N.S., Barrett, N.J., Stanwell-Smith, R., 1987. Water and disease after croydon: a review of water-borne and water-associated disease in the UK 1937-86. Water Environ. J. 1 (1), 7-21.

Glassmeyer, S.T., Furlong, E.T., Kolpin, D.W., Cahill, J.D., Zaugg, S.D., Werner, S.L., Kryak, D.D., 2005. Transport of chemical and microbial compounds from known wastewater discharges: potential for use as indicators of human fecal contamination. Environ. Sci. Technol. 39 (14), 5157-5169.

Goodman, R.A., Buehler, J.W., Greenberg, H.B., Mckinley, T.W., Smith, J.D., 1982 Norwalk gastroenteritis associated with a water system in a rural Georgia community. Arch. Environ. Health 37 (6), 358-360.

Graham, J.P., Polizzotto, M.L., 2013. Pit latrines and their impacts on groundwater quality: a systematic review. Environ. Health Perspect. 121 (5), 521.

Hänninen, M.L., Haajanen, H., Pummi, T., Wermundsen, K., Katila, M.L. Sarkkinen, H., Rautelin, H., 2003. Detection and typing of Campylobacter jejun and Campylobacter coli and analysis of indicator organisms in three waterborne outbreaks in Finland. Appl. Environ. Microbiol. 69 (3).

Howard, G., Pedley, S., Barrett, M., Nalubega, M., Johal, K., 2003. Risk factors contributing to microbiological contamination of shallow groundwater in Kampala, Uganda. Water Res. 37 (14), 3421-3429.

Horn, B.J., Lake, R.J., 2013. Incubation period for campylobacteriosis and its importance in the estimation of incidence related to travel. Euro Surveill. 18, 20602.

Howe, A.D., Forster, S., Morton, S., Marshall, R., Osborn, K.S., Wright, P., Hunter, P.R., 2002. Cryptosporidium oocysts in a water supply associated with a cryptosporidiosis outbreak. Emerg. Infect. Dis. 8 (6), 619.

Hynds, P.D., Misstear, B.D., Gill, L.W., 2012. Development of a microbial contamination susceptibility model for private domestic groundwater sources. Water Resour. Res. 48 (12).

Hynds, P.D., Misstear, B.D., Gill, L.W., 2013. Unregulated private wells in the Republic of Ireland: consumer awareness, source susceptibility and protective actions. J. Environ. Manag. 127, 278-288.

Hynds, P.D., Thomas, M.K., Pintar, K.D.M., 2014a. Contamination of groundwate systems in the US and Canada by enteric pathogens, 1990-2013: a review and pooled-analysis. PLoS One 9 (5), e93301.

Hynds, P.D., Gill, L.W., Misstear, B.D., 2014b. A quantitative risk assessment of verotoxigenic E. coli (VTEC) in private groundwater sources in the Republic of Ireland. Hum. Ecol. Risk Assess. 20 (6), 1446-1468.

Ivers, L.C., Ryan, E.T., 2006. Infectious diseases of severe weather-related and floodrelated natural disasters. Curr. Opin. Infect. Dis. 19 (5), 408-414.

Jack, S., Bell, D., Hewitt, J., 2013. Norovirus contamination of a drinking water supply at a hotel resort. N. Z. Med. J. (Online) 126 (1387).

Jin, Y., Flury, M., 2002. Fate and transport of viruses in porous media. Adv. Agron. 77, 39-102.

Karmali, M.A., Gannon, V., Sargeant, J.M., 2010. Verocytotoxin-producing Escherichia coli (VTEC). Vet. Microbiol. 140 (3), 360-370.

Katz, B.G., Griffin, D.W., Davis, J.H., 2009. Groundwater quality impacts from the land application of treated municipal wastewater in a large karstic spring basin: chemical and microbiological indicators. Sci. Total Environ. 407 (8), 2872-2886.

Kendon, E.J., Roberts, N.M., Fowler, H.J., Roberts, M.J., Chan, S.C., Senior, C.A., 2014 Heavier summer downpours with climate change revealed by weather forecast resolution model. Nat. Clim. Change 4 (7), 570-576.

Kreutzwiser, R., de Loë, R., Imgrund, K., Conboy, M.J., Simpson, H., Plummer, R., 2011. Understanding stewardship behaviour: factors facilitating and constraining private water well stewardship. J. Environ. Manag. 92 (4), 1104-1114.

Kríz, B., Benes, C., Castkova, J., Helcl, J., 1998. Monitoring of the epidemiological situation in flooded areas of the Czech Republic in year 1997. In: Proceedings of the Conference DDD, vol. 98, pp. 11-12.

Kukkula, M., Arstila, P., Klossner, M.L., Maunula, L., Bonsdorff, C.H.V., Jaatinen, P., 1997. Waterborne outbreak of viral gastroenteritis. Scand. J. Infect. Dis. 29 (4), 415-418.

Lee, C.C., 2005. Environmental Engineering Dictionary, fourth ed. Government Institutes.

Margat, J., Van der Gun, J., 2013. Groundwater Around the World: a Geographic Synopsis. CRC Press.

Mårtensson, P., Fors, U., Wallin, S.B., Zander, U., Nilsson, G.H., 2016. Evaluating research: a multidisciplinary approach to assessing research practice an quality. Res. Pol. 45 (3), 593-603.

Miettinen, I., Zacheus, O., Von Bonsdorff, C., Vartiainen, T., 2001. Waterborne epidemics in Finland in 1998-1999. Water Sci. Technol. 43 (12), 67-71.

Mouly, D., Van Cauteren, D., Vincent, N., Vaissiere, E., Beaudeau, P., Ducrot, C., Gallay, A., 2016. Description of two waterborne disease outbreaks in France: a comparative study with data from cohort studies and from health administrative databases. Epidemiol. Infect. 144 (3), 591-601.

Mousavi, M.E., Irish, J.L., Frey, A.E., Olivera, F., Edge, B.L., 2011. Global warming and hurricanes: the potential impact of hurricane intensification and sea level rise on coastal flooding. Climatic Change 104 (3), 575-597.

Murphy, H.M., Prioleau, M.D., Borchardt, M.A., Hynds, P.D., 2017. Epidemiological evidence of groundwater contribution to global enteric disease, 1948-2015. Hydrogeol. J. 25 (4), 981-1001.

O'Dwyer, J., Dowling, A., Adley, C., 2014. Microbiological assessment of private groundwater-derived potable water supplies in the Mid-West Region of Ireland. J. Water Health 12 (2), 310-317.

O'Dwyer, J., Downes, M.M., Adley, C.C., 2016. The impact of meteorology on the occurrence of waterborne outbreaks of verocytotoxin-producing Escherichia coli (VTEC): a logistic regression approach. J. Water Health 14 (1), 39-46.

O'Neill, E., 2017. Expanding the horizons of integrated flood risk management: a critical analysis from an Irish perspective. Int. J. River Basin Manag. 1-7.

Owrangi, A.M., Lannigan, R., Simonovic, S.P., 2014. Interaction between land-use change, flooding and human health in Metro Vancouver, Canada. Nat. Hazards $72(2), 1219-1230$

Pall, P., Aina, T., Stone, D.A., Stott, P.A., Nozawa, T., Hilberts, A.G., Allen, M.R., 2011. Anthropogenic greenhouse gas contribution to flood risk in England and Wales in autumn 2000. Nature 470 (7334), 382-385.

Pronk, M., Goldscheider, N., Zopfi, J., 2009. Microbial communities in karst groundwater and their potential use for biomonitoring. Hydrogeol. J. 17 (1), $37-48$.

Reacher, M., McKenzie, K., Lane, C., Nichols, T., Kedge, I., Iversen, A., Simpson, J., 2004. Health impacts of flooding in Lewes: a comparison of reported gastrointestinal and other illness and mental health in flooded and nonflooded households. Comm. Dis. Publ. Health/PHLS 7 (1), 39-46.

Risebro, H.L., Doria, M.F., Andersson, Y., Medema, G., Osborn, K., Schlosser, O., Hunter, P.R., 2007. Fault tree analysis of the causes of waterborne outbreaks. J. Water Health 5 (S1), 1-18.

Rojas, R., Feyen, L., Watkiss, P., 2013. Climate change and river floods in the European Union: socio-economic consequences and the costs and benefits of adaptation. Global Environ. Change 23 (6), 1737-1751.

Sargeant, J.M., Rajic, A., Read, S., Ohlsson, A., 2006. The process of systematic review and its application in agri-food public-health. Prev. Vet. Med. 75 (3), 141-151.

Semenza, J.C., Menne, B., 2009. Climate change and infectious diseases in Europe. Lancet Infect. Dis. 9 (6), 365-375.

Semenza, J.C., Suk, J.E., Estevez, V., Ebi, K.L., Lindgren, E., 2012. Mapping climate change vulnerabilities to infectious diseases in Europe. Environ. Health Perspect. 120 (3), 385.

Ten Veldhuis, J.A.E., Clemens, F.H., Sterk, G., Berends, B.R., 2010. Microbial risks associated with exposure to pathogens in contaminated urban flood water. Water Res. 44 (9), 2910-2918.

Uejio, C.K., Christenson, M., Moran, C., Gorelick, M., 2017. Drinking-water treatment, climate change, and childhood gastrointestinal illness projections for northern Wisconsin (USA) communities drinking untreated groundwater. Hydrogeol. J. $1-11$.

Unc, A., Goss, M., 2003. Movement of faecal bacteria through the vadose zone. Water, Air and Soil 149, 327-337.

United Nations, 2017. World Economic Situation and Prospects 2017. Available at: https://www.un.org/development/desa/dpad/wpcontent/uploads/sites/45 publication/2017wesp_full_en.pdf. (Accessed 3 November 2017).

US EPA, 2015. Private drinking water wells. Retrieved from. http://www2.epa.gov/ privatewells. (Accessed 19 October 2017).

Wallender, E.K., Ailes, E.C., Yoder, J.S., Roberts, V.A., Brunkard, J.M., 2014. Contributing factors to disease outbreaks associated with untreated groundwater. Groundwater 52 (6), 886-897.

Zektser, I., Everett, L., 2004. Groundwater Resources of the World and Their Use, IHP-VI, Series on Groundwater. United Nations Educational, Scientific and Cultural Organization. 